\title{
Effect of ion implantation on the physical and mechanical properties of Ti-Si-N multifunctional coatings for biomedical applications
}

\author{
A. Shypylenko a,b,*, A.V. Pshyk ${ }^{\text {a,b }}$, B. Grześkowiak ${ }^{\text {a }}$, K. Medjanik ${ }^{c}$, B. Peplinska a , K. Oyoshi ${ }^{\text {d }}$, A. Pogrebnjak ${ }^{\text {b }}$, \\ S. Jurga ${ }^{\mathrm{a}, \mathrm{e}}$, E. Coy ${ }^{\mathrm{a}, *}$
}

a NanoBioMedical Centre, Adam Mickiewicz University, Umultowska 85, PL 61614 Poznań, Poland

b Sumy State University, Rymskogo-Korsakova 2, 40007 Sumy, Ukraine

c Lund University, MAX IV Laboratory, Fotongatan 2, 22592 Lund, Sweden

${ }^{\mathrm{d}}$ National Institute for Material Science (NIMS), 3-13 Sakura, 305-0003 Tsukuba, Ibaraki, Japan

e Department of Macromolecular Physics, Adam Mickiewicz University, Umultowska 85, 61-614 Poznań, Poland

\section{H I G H L I G H T S}

- Ternary coatings of the Ti-Si-N system were deposited by CAVD method.

- $\mathrm{Cu}$ ions with energy of $60 \mathrm{keV}$ and dosage of $\mathrm{D}=2 \times 10^{17}$ ions $/ \mathrm{cm}^{2}$ were implanted.

- A Cu concentration of up to $25 \%$ at a depth of $25 \mathrm{~nm}$ (maximum implantation depth of $60 \mathrm{~nm}$ ) was achieved.

- Mechanical properties of the coating have been negatively affected by ion implantation.

- The low dosage of $\mathrm{Cu}$ ions did not show any antibacterial activity on the samples, while a rapid release of $\mathrm{Cu}$ was observed.

\section{A R T I C L E I N F O}

\section{Article history:}

Received 17 June 2016

Received in revised form 28 July 2016

Accepted 15 August 2016

Available online 20 August 2016

\section{Keywords:}

TiSiN

Coatings

Antibacterial

Ion implantation

NEXAFS

CAVD

\section{GRAPHICALABSTRACT}

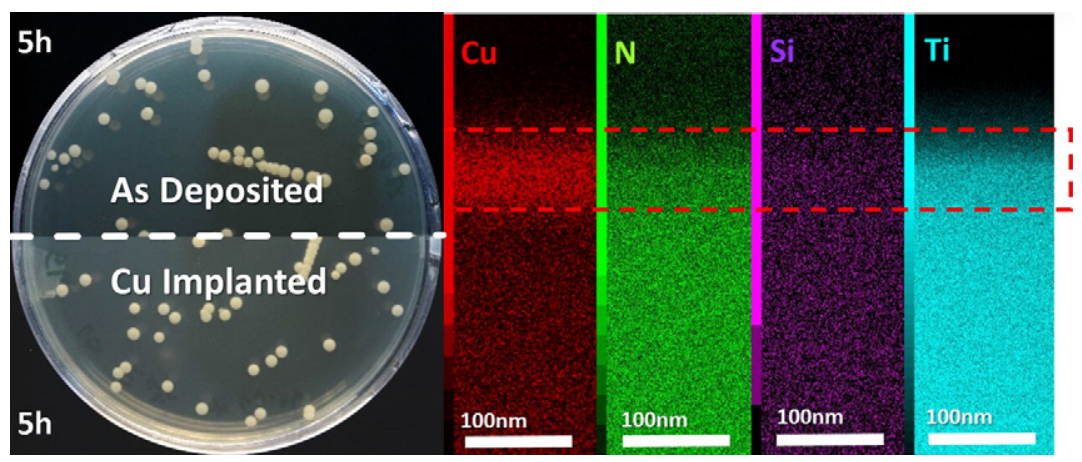

\begin{abstract}
A B S T R A C T
In the present work, multifunctional Ti-Si-N coatings have been deposited using CAVD method with the aim of studying their chemical, physical, structural and mechanical properties. Coatings of Ti-Si-N were modified by high-intensity ion implantation using copper ions with dose $\mathrm{D}=2 \times 10^{17} \mathrm{ions} / \mathrm{cm}^{2}$ and energy $\mathrm{E}=60 \mathrm{keV}$. The results demonstrated that ion implantation has an effect on the grain size, hardness, and Young modulus of the Ti-Si-N coating. Additionally, the effect of $\mathrm{Cu}$ implantation on the bioactive properties of coatings was investigated by contact antimicrobial essay. The results show a high release of $\mathrm{Cu}$ ions in the cultivation liquid and the low efficiency of the $<20 \%$ Cu doping towards E. coli bacteria. Our results bring understanding to the low dosage ion implantation of multifunctional surfaces towards applications and general drawbacks of ion implantation as bioactive tailoring method.
\end{abstract}

(C) 2016 Published by Elsevier Ltd.

\footnotetext{
* Corresponding authors at: NanoBioMedical Centre, Adam Mickiewicz University, Umultowska 85, PL 61614 Poznań, Poland

E-mail addresses: andshy@amu.edu.pl (A. Shypylenko), coyeme@amu.edu.pl (E. Coy).
}

\section{Introduction}

Nowadays, one of the priorities in the development of science and technology is the creation and manufacture of novel materials. These efforts are fuelled by the increasing interest and applicability of the nanomaterials. An important area of research in nanomaterials and 
nanotechnology is the surface engineering, which includes the creation of multi-component (multi-function) nanostructured surfaces. This is the case of protective coatings and more specifically nanocomposite coatings, in which nanocrystalline phases, typically of tens of nanometers [1-8] are embedded in an amorphous matrix.

The uniqueness of the nanostructured coatings resides in the high volume fraction of nanocomposites, their superior strength, resilience to dislocations, the possibility of controlling the ratio of volume fractions of crystalline and amorphous phases, and the possibility of mutual coexistence of metallic and nonmetallic elements [9]. Moreover, the bigger volume fraction of the nanostructured phases in the coatings, allows the careful control of the coating properties by modifying their structure and chemical composition. All of these factors allow the creation of nanostructured coatings with improved physico-chemical and tribological properties, which in practice, translate in high values of hardness ( $\mathrm{H}>40 \mathrm{GPa}$ ), Young's modulus, strength, thermal stability, and heat and corrosion resistance $[6,10]$. It is important to mention that a special feature of these so-called superhard materials, in which materials with the same hardness may exhibit different values of the elastic modulus (E), as well as resistance to elastic strain, to failure $(\mathrm{H} / \mathrm{E})$ and resistance to plastic deformation $\left(\mathrm{H}^{3} / \mathrm{E}^{2}\right)[9]$.

Current industrial trends widely use coatings based on titanium nitride (TiN) [5-8]. TiN coatings have a broad range of applications such as: dental prosthesis, materials for hip joint and heart valve replacements [11]. This wide applicability is due to the fact that TiN films possess a combination of useful properties such as high hardness, wear/ corrosion resistance, as well as biocompatibility, all of which have been exhaustively investigated [12]. TiN and $\mathrm{TiO}_{2}$ films have been known to possess excellent hemocompatibility $[9,13]$, equally important are the results of $\mathrm{SiO}_{2}$ and $\mathrm{TiO}_{2}$ ceramics which have shown to promote the formation of Apatite due to the electronegative surface if TiO in a broad range of $\mathrm{pH}$ [14], an important results for implantology. Nevertheless, coatings with a broad range of applications have been studied an proposed in the literature, such as: nitrides (TiN, NbN, $\mathrm{ZrN}, \mathrm{CrN}$, AlN, etc.), borides ( $\mathrm{TiB}_{2}, \mathrm{NbB}_{2}, \mathrm{ZrB} 2$, among others), and oxides $\left(\mathrm{TiO}_{2}\right.$, $\mathrm{SiO}_{2}, \mathrm{NbO}_{2}$, and $\left.\mathrm{ZrO}_{2}\right)[3,4,7]$.

For biomedical purposes, a wide range of ceramic materials have been used, such as: $\mathrm{TiN}, \mathrm{ZrO}, \mathrm{TiO}_{2}, \mathrm{SiO}_{2}$ and some metal-carbides [15] all of which have shown applicability in implantology $[16,17,18]$. Unfortunately, the high loads required for many orthopaedic and dental implants restrict the selection of biomaterials [12]. Thus, metals and alloys stand up as a type of materials that meet many of these mechanical requirements. [19,20]. Nevertheless, the control of chemical composition of such functional coatings, i.e.: by adding a third component such as $(\mathrm{Si})$, may enable them to significantly improve their mechanical properties and therefore extend their applicability [3,5]. A great interest to the Ti-Si-N coatings resides on their high hardness ( $\geq 40 \mathrm{GPa}$ ), thermal stability $\left(1100{ }^{\circ} \mathrm{C}\right)$, resistance to oxidation at high temperatures $\left(600{ }^{\circ} \mathrm{C}\right)$ and high resistance to abrasion $[13,21,22]$.

A common approach used to improve the tribological properties of TiN coatings is to apply a high-dose ion implantation [23]. The literature provides sufficient evidence to support the statement that the ion implantation of several atoms $\mathrm{N}, \mathrm{W}, \mathrm{Ni}$, Mo and $\mathrm{Al}$, can lead to the improvement of the tribological properties of protective coatings [24]. Investigation of the $\mathrm{N}$ ion implantation at dose of $1 \times 10^{17}, 5 \times 10^{17}$ and $1 \times 10^{18}$ ions $/ \mathrm{cm}^{2}$ on Tungsten metal have revealed that the dose of $1 \times 10^{18}$ ions $/ \mathrm{cm}^{2}$ could obtain a significant reduction in the friction coefficient of the surfaces [25]. Investigation on the effects of W implantation on the TiN coating shows that increasing implanted materials in the coating can increase hardness and reduce the rate of wear and coefficient of friction [26].

Additionally, ion implantation is one of the most important methods of materials treatment today, and allows the improvement of physicalmechanical properties. Surface properties of materials can be improved without visible changes in the geometry of the samples, furthermore, it introduces different chemical elements into the material, thus changing its surface chemistry. Remarkably enough, it was shown that ion implantation by $\mathrm{Cu}, \mathrm{Ni}$ or $\mathrm{Ti}$, in the TiN based coatings, can lead to the fabrication of nanocomposites coatings, known for their enhanced mechanical and tribological properties [23]. In addition, it has been also shown that by adding $\mathrm{Cu}$ into the nanostructured of nanocomposite coatings their bacteriological properties can be improved [24]. Metal ion implantation in nanostructured or nanocomposite coatings has shown to be a very efficient and promising instrument of controlling and tailoring their physical and functional properties.

Antibacterial tests performed on $\mathrm{Cu}$ implanted surfaces have shown that the $\mathrm{Cu}$ content strongly influences the antibacterial efficiency of the surfaces, especially in cases when the Cu content reaches values higher than $20 \mathrm{wt}$.\%. Not much consensus is found on the specific reason behind the lack of antibacterial activity on low $\mathrm{Cu}$ implanted surfaces, although it is generally attributed to their high roughness and low release rates of $\mathrm{Cu}^{2+}$ [27]. Conversely, high $\mathrm{Cu}$ ion doping induces higher release of $\mathrm{Cu}$ ion from the surface. A high release rate was observed for Ti-Cu alloys with high $\mathrm{Cu}>20 \%$ content [28], which seems to suggest that low doped surfaces have similar effect, but due to the relatively low $\mathrm{Cu}$ ions in the surface, no visible antibacterial activity is reported. Nevertheless, it is quite clear that the Ti-Cu phase should play an important role in a strong antibacterial activity as reported in the literature [29]. Additionally, Cu doping could lead to excellent corrosion resistance and workability of the surfaces, which ultimately has driven important attention of many research groups [29-32].

Although Ti based surfaces are widely applied in the biomedical sector and $\mathrm{Cu}$ implantation is commonly acknowledged as an efficient route of tailoring antibacterial surfaces and coatings, there are no studies on the effect of low $\mathrm{Cu}$ implantation on Ti-Si-N based coatings, on their physical, mechanical and bioactive properties. This article aims to investigate the effect of low Cu doping on the physical and bioactive properties of Ti-Si-N coatings in order to explore their potential applications in biomedicine.

\subsection{Experimental details}

Coatings were deposited on A570(36) (steel 3) substrates with polished surface. Substrate dimensions were $\varnothing=18 \mathrm{~mm}$ and $t=$ $3 \mathrm{~mm}$. Coatings were deposited using the cathodic vacuum-arc evaporation (CAVD) technique, operating with $\mathrm{Ti}$ and Si cathodes in a nitrogen atmosphere under a high-current. Thickness of the fabricated TiSi-N coatings was around $1.2 \mu \mathrm{m}$. Deposition parameters are presented in the Table 1. The sample was divided into several pieces in order to investigate the influence of ion implantation on the physical-mechanical properties of the Ti-Si-N coatings. Ion implantation was performed using an ion gun of negative copper ions $\left(\mathrm{Cu}^{-}\right)$[33] with accelerating voltage $\mathrm{E}=60 \mathrm{keV}$, implantation dose was $\mathrm{D}=2 \times 10^{17} \mathrm{ion} / \mathrm{cm}^{2}$.

\subsection{Coatings characterization}

Elemental composition was investigated using Rutherford Backscattering (RBS) of $4 \mathrm{He}^{+}$ions with energy of $1.7 \mathrm{MeV}$, detector resolution was $\mathrm{E}=13 \mathrm{keV}$, scattering angle was $170^{\circ}$. Scanning electron microscopy with energy dispersive analysis (SEM with EDX) was also used (JEOL 7001TTLS) in direct and backscattered modes, as well as in elemental

Table 1

Important instrumental parameters in the fabrication of the Ti-Si-N coatings by CAVD.

\begin{tabular}{ll}
\hline Parameters & Values \\
\hline Working pressure $\mathrm{N}_{2}(\mathrm{~Pa})$ & 0.3 \\
Ti target current $(\mathrm{A})$ & 100 \\
Si targets current $(\mathrm{A})$ & 100 \\
Substrate temperature $\left({ }^{\circ} \mathrm{C}\right)$ & $>300$ \\
Negative bias voltage $(\mathrm{V})$ & -70 \\
Deposition time $(\mathrm{min})$ & 220 \\
\hline
\end{tabular}


contrast. Further elemental characterization of the surface was performed by X-ray characterizing irradiation, induced by proton microbeam ( $\mu$-PIXE). A scan size of $200 \times 200 \mu \mathrm{m}$ was used on part of the coating's surface, cross-probe size was $4 \times 4 \mu \mathrm{m}$, charge $Q=4 \times 10^{-10} \mathrm{C}$ / pixel, bitmap $50 \times 50$ pixels, scanning step $4 \mu \mathrm{m}$, energy of protons $\mathrm{Ep}=1.5 \mathrm{MeV}$. Here, a pixel refers to a stationary position of the probe during discrete scan. $\mu$-PIXE spectra were processed using GUPIX software.

Phase composition and structural investigations were done using $\mathrm{X}$ ray diffractometer PANalytical with filtered Cu-K $\alpha$ radiation (1.5418 $\AA$ ) with PIXcel 3D detector in Bragg-Brentano geometry. Spectra were recorded in continuous scanning mode at room temperature $(300 \mathrm{~K})$, the swept angle was $25.0-80.0$ [ ${ }^{\circ} 2 \mathrm{Th}$.], scanning step was 0.007 [ ${ }^{\circ} 2 \mathrm{Th}$.] for as-deposited Ti-Si-N samples and 0.0025 [ ${ }^{\circ} 2 \mathrm{Th}$.] for implanted Ti-Si-N samples. Size of crystallites was evaluated using Scherrer method from the width of the widest band on 37.3372 [ ${ }^{\circ}$ Th.]. Data were processed in the PANalytical X'Pert software.

Near Edge X-ray Absorption Fine Structure (NEXAFS) experiment has been performed the soft X-ray beamline of the MAX II storage ring at MAX IV lab - Lund University. Accessible energy range is 120 to $2000 \mathrm{eV}$, with an energy resolving power of around 5000 at the lowest used photon energies. Beamline equipped with a collimated plane grating monochromator and an elliptically polarizing undulator, providing almost $100 \%$ linearly and circularly polarized radiation. All measurements were done at room temperature in the so-called "octupole" end station in total electron yield mode (TEY). The advantage of this method is the bulk sensitivity, allowing the investigation of depth information, from 3 to $5 \mathrm{~nm}$ depending on studied object and impact angle of the $\mathrm{X}$-ray beam. Two samples (Ti-Si-N after ion implantation by $\mathrm{Cu}^{-}$ions with $\mathrm{D}=2 \times 10^{17}$ ions $/ \mathrm{cm}^{2}, \mathrm{E}=60 \mathrm{keV}$ and pure Ti-Si-N) were carefully fixed to the sample holder and loaded into the experimental chamber.

Cross-sections for High Resolution Transmission Electron Microscopy (HR-TEM) were prepared using focused ion beam (FIB) JEOL JIB4000. Initially a carbon film was applied on top of a rectangular region, in order to protect the sample from the Ga ion beam. Lamellae were then milled down to electron transparency using $\mathrm{Ga}^{+}$ion beam with different energy (5-30 keV). HR-TEM measurements were performed on JEOL-ARM $200 \mathrm{~F}$ ( $200 \mathrm{kV}$ ) equipped with a EDX detector.

Finally, nanohardness and elastic modulus were measured using nanoindentation (Hysitron TI 950 TriboIndenter) with Berkovich diamond indenter. Several tests were conducted at different places of the coating using a maximum load of $10,000 \mu \mathrm{N}$. We evaluated values of hardness and elasticity modulus from load-unload curves using Oliver-Pharr method [4-6,8-10].

\subsection{Antimicrobial activity determination}

The antibacterial activity of the samples was tested on the $E$. coli bacteria using dynamic shake flask method. The bacterial cells were cultured in $5 \mathrm{ml}$ of Luria broth in a sterile $15 \mathrm{ml}$ conical tube. The culture was incubated at $37^{\circ} \mathrm{C}$ while being shaken at $220 \mathrm{rpm}$ (MaxQ600 Shaker, Thermo Scientific) for 18-20 h. The culture was then washed twice with sterilized saline $(0.9 \% \mathrm{NaCl})$ solution by centrifugation for $10 \mathrm{~min}$ and then the cell pellet was re-suspended in sterilized saline solution. The actual number of cells used for a given experiment was determined by standard serial dilution. Samples with implanted surface and asdeposited surface were tested and compared, samples were shaken with $5 \mathrm{ml}$ of a bacterial suspension containing $2 \times 10^{5} \mathrm{CFU} / \mathrm{ml}$. Then, the suspension was taken after $1 \mathrm{~h}$ and $5 \mathrm{~h}$ of incubation in $37^{\circ} \mathrm{C}$ and diluted appropriately. Then $25 \mu \mathrm{l}$ of the suspension containing 1010 cells was applied to the surface of as-deposited and implanted surfaces for a comparison, experiments were carried out for 1 and $5 \mathrm{~h}$. The suspension was held in contact with the sample by a sterilized glass plate. The ambient temperature was $24^{\circ} \mathrm{C}$. After exposure, the sample and glass plate were washed in $5 \mathrm{ml}$ of the saline solution and a new diluted suspension was formed. Then, $100 \mu \mathrm{l}$ of this new diluted suspension was transferred and spread on the surface of Petri dish covered with the Lagar. The agar covered with new diluted suspension was cultivated for $24 \mathrm{~h}$ in incubator at $37^{\circ} \mathrm{C}$. The grown $\mathrm{E}$. coli colonies were clearly visible and were counted.

\section{Results and discussion}

Structural characterization is shown in Fig. 1 where the XRD patterns of the Ti-Si-N coatings as-deposited (Fig. 1a) and after ion implantation by $\mathrm{Cu}^{-}$ions with $\mathrm{D}=2 \times 10^{17}$ ions $/ \mathrm{cm}^{2}, \mathrm{E}=60 \mathrm{keV}$ (Fig. $1 \mathrm{~b}$ ) are presented. It was found that all the Ti-Si-N coatings had a polycrystalline structure with strong contribution of crystal planes orientations of TiN (111) and $\mathrm{Ti}_{2} \mathrm{~N}(200)$.

Experiments show that TiN was stabilized (ICCD: 01-087-0629) and $\mathrm{Ti}_{2} \mathrm{~N}$ (ICCD: 00-023-1455). However, the values are compatible with the solid solution (Ti, Si)N (ICCD: 04-001-9273) which is congruent with the nominal stoichiometry of the target. We calculated the lattice parameter $\mathrm{a}_{0}=4.240 \AA$ corresponding to fcc (111) and (222) crystal system for TiN, the lattice parameter $\mathrm{a}_{0}=4.09 \AA$ A corresponding to bcc (112), (103) and (200) crystal system for $\mathrm{Ti}_{2} \mathrm{~N}$. Analysis of the calculated lattice data, in particular TiN lattice parameter after ions implantation, indicates a slight expansion of the lattice in the direction (111) $0.0153 \AA$ and direction $(222)-0.0045 \AA$. The broadening of these lines can be attributed to the effect of the ion implantation by increasing
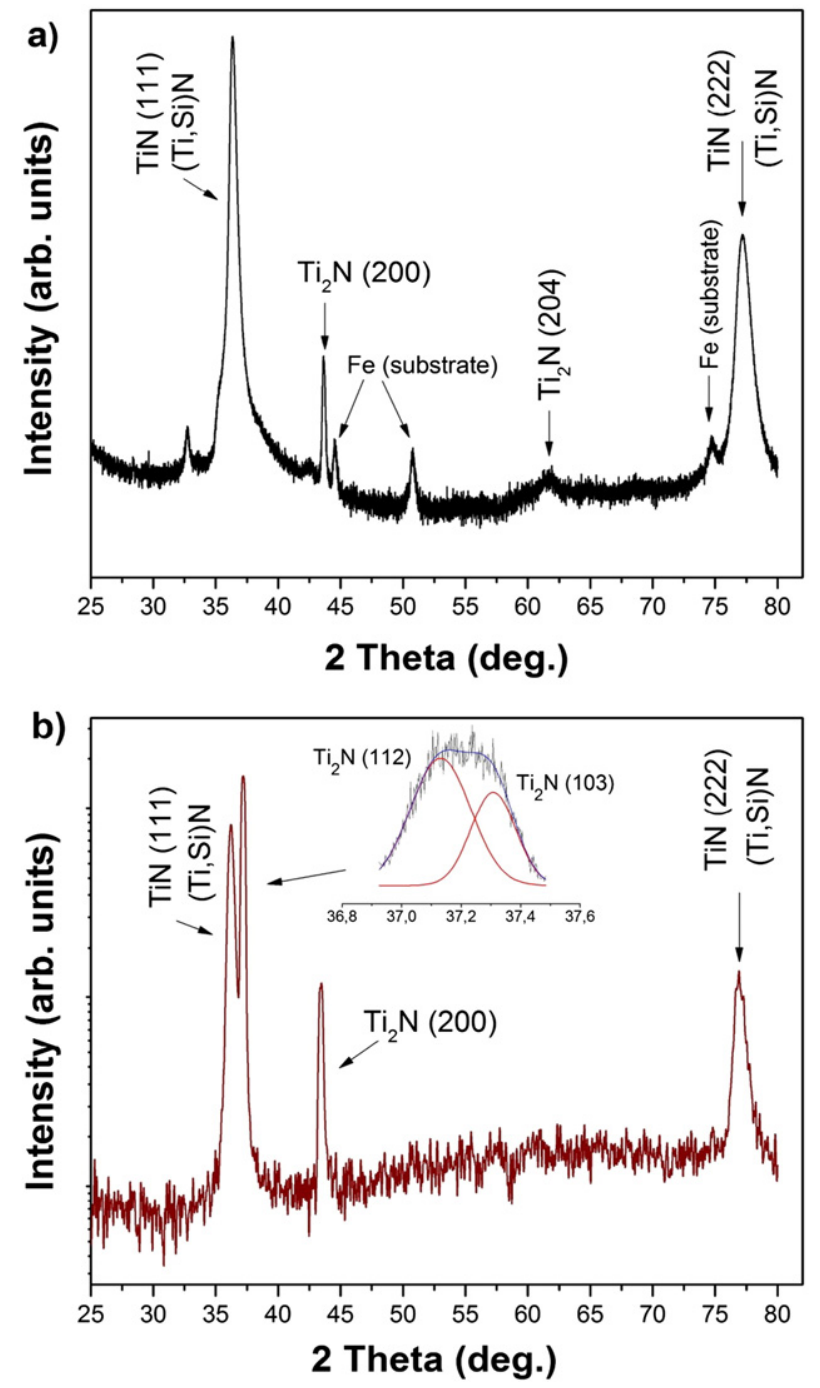

Fig. 1. Ti-Si-N coating's X-ray diffraction patterns: a) as-deposited; b) after ion implantation by $\mathrm{Cu}^{-}$ions with $\mathrm{D}=2 \times 10^{17}$ ions $/ \mathrm{cm}^{2}, \mathrm{E}=60 \mathrm{keV}$. 
the misalignment of the grains. Due to similarity of the atomic radii of titanium and copper ( $\mathrm{Ti}=140 \mathrm{pm}, \mathrm{Cu}=135 \mathrm{pm}$ ), it can be assumed that the copper ions can create vacancy defect by knocking out titanium atoms from the unit cells, promoting further substitution at both nodes and intermediate positions between lattice sites, thus creating a lattice stresses.

Evaluation of coherent-scattering region (using Scherrer method) showed that the size of nanograins increase from $42.1 \mathrm{~nm}$ (as-deposited) to $54.55 \mathrm{~nm}$ (after implantation) for TiN, while for as-deposited $\mathrm{Ti}_{2} \mathrm{~N}$ nanograins this value is reduced from $39.82 \mathrm{~nm}$ to $33.56 \mathrm{~nm}$ after implantation. Ion implantation is known to induce the decreasing of both transverse and longitudinal sizes of grains [33]. This behaviour is congruent with previous observations, in which high ion implantation lead to a significant decrease of the grain sizes [34]. Nanograins boundaries play an important role in hardening of the material, because they are a barrier for flow spread, as well as dislocations, which form the shear stresses. Therefore, ion implantation, which leads to decreasing of the grain size, might improve the hardness of investigated coatings according to the literature $[34,35]$.

After modelling the XRD pattern of the as-deposited coating using the Rietveld-Toraya model and pseudo-Voigt function [36] in the Powder Cell program [37] and calculating their corresponding volume fraction, a contribution of the cubic phase TiN equal to $66 \%$, and tetragonal phase $\mathrm{Ti}_{2} \mathrm{~N}$ equal to $34 \%$ was found. The analysis of the coating after implantation shows a volume fraction equal to $16.7 \%(\mathrm{TiN})$, and $83.3 \%$ $\left(\mathrm{Ti}_{2} \mathrm{~N}\right)$. This may indicate that the ion implantation promoted the recrystallization in the coating, which is usually accompanied by a reduction in the strength and hardness of a material and a simultaneous increase in the ductility [4].

Images of the coatings' surface before and after ion implantation by $\mathrm{Cu}^{-} 2 \times 10^{17}$ ions $/ \mathrm{cm}^{2}$ are shown in Fig. 2 . As it can be observed, the surface of the coating has a considerable amount of droplets (Fig. 2a,b), which appeared during the deposition of coating by the CAVD. Thus, it is important to remind that a small part of plasma jet in this technique consist of micro droplets. Elemental composition (EDX) of both coatings, as deposited and after ion implantations by $\mathrm{Cu}^{-}(\mathrm{D}=$
$2 \times 10^{17}$ ions $/ \mathrm{cm}^{2}, \mathrm{E}=60 \mathrm{keV}$.) is shown in Fig. $2 \mathrm{c}$ and $\mathrm{d}$, the spectra shows an increase of the $\mathrm{C}$ and $\mathrm{O}$ content, after ion implantation.

From the EDX analysis, the elemental composition of the coating after $\mathrm{Cu}$ implantation is extracted as: $\mathrm{N}=46.8$ at.\%, $\mathrm{Ti}=35.99$ at.\%, $\mathrm{Cu}=2.19$ at.\%, $\mathrm{Si}=0.30$ at.\%, $\mathrm{O}=3.58$ at.\% and $\mathrm{C}=10.64$ at.\%. The nominal composition is compatible with that of previously reported samples of Ti-Si-N nanocomposite coatings, $\mathrm{N}=54.918$ at.\%, $\mathrm{Ti}=$ 38.78 at.\%, $\mathrm{Si}=0.418$ at.\% [37,38]. Additional analysis regarding the elemental composition of the coatings was done using RBS technique (Fig. 3). In the figure, two backscattering spectra are presented: from Ti-Si-N coating as-deposited (Fig. 3a) and after ion implantation (Fig. 3b). According to RBS data, the as-deposited coating mainly consists of Ti, Si and N. The RBS analysis of elemental composition of the $\mathrm{Cu}$ implanted (see Fig. 3c) shows that maximal concentration of the $\mathrm{Cu}$ ions is around 20 at.\% near the surface of the coating. We marked the boundaries of kinematic factors of $\mathrm{N}, \mathrm{O}, \mathrm{Si}, \mathrm{Ti}$ and $\mathrm{Cu}$ elements. Standard software allowed to receive profiles of elements over the depth of the coating after implantation by $\mathrm{Cu}^{-}$ions. It can be observed in Fig. 3c, that maximum concentration of implanted ions is observed at a depth of 20$40 \mathrm{~nm}$ and that $\mathrm{Cu}$ ions reach a maximun depth of $\approx 60 \mathrm{~nm}$. Oxidized silicon film was also observed at deeper regions, which can be atributed to the ballistic mixing and high density of cascades of collisions between heavy copper ions. Since the $\mathrm{Cu}$ implantation was not done in-situ, oxidation of the coating could have started or humidy might have been adsobed on the surface, then, $\mathrm{Cu}$ ions pushed their way inside the coating doping the system with surface contaminants. Nevertheless, studies show that Ti, Si and N are the main components of the coating, which are the basis of the (Ti, Si)N solid solution. High concentration of nitrogen was found on the surface of the coating, with a homogeneous distribution over the investigated depth of the coating.

Maps of distribution of elements from the $4 \times 4 \mu \mathrm{m}$ part of the Ti-Si$\mathrm{N}$ coating are presented on the Fig. $4 \mathrm{a}$ (as-deposited coating) and Fig. $4 \mathrm{~b}$ (after ion implantation by $\mathrm{Cu}^{-}$ions with $\mathrm{D}=2 \times 10^{17}$ ions $/ \mathrm{cm}^{2}, \mathrm{E}=$ $60 \mathrm{keV}$ ), scanning step was $4 \mu \mathrm{m}$. Plots clearly show that the distribution of elements is homogeneous on the surface and over the depth studied. Ion implantation led to decrease in Ti concentration and localizing of Si
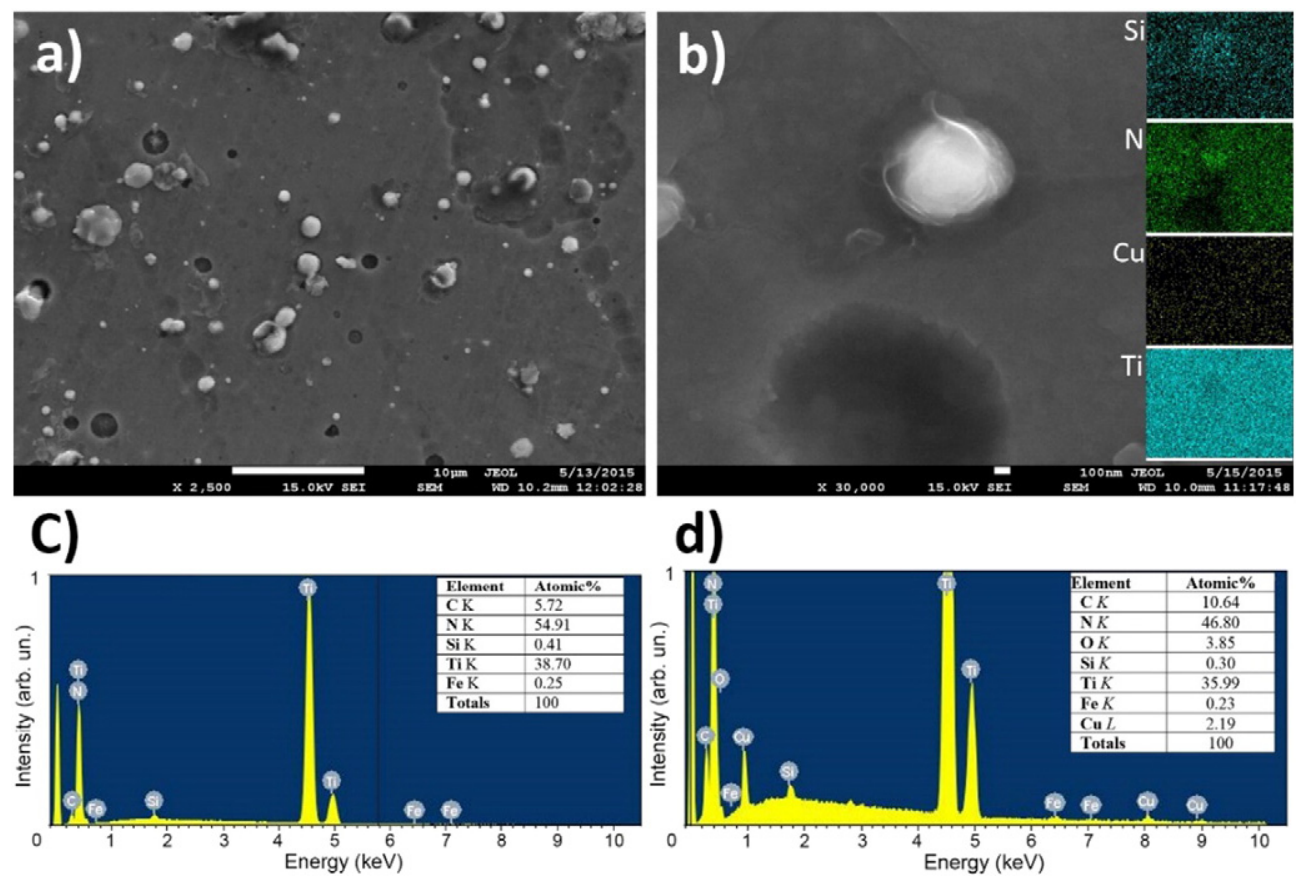

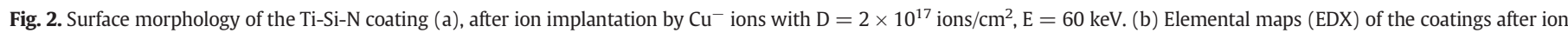
implantation. EDX spectrograms of as deposited coating (c) and after implantation (d). 

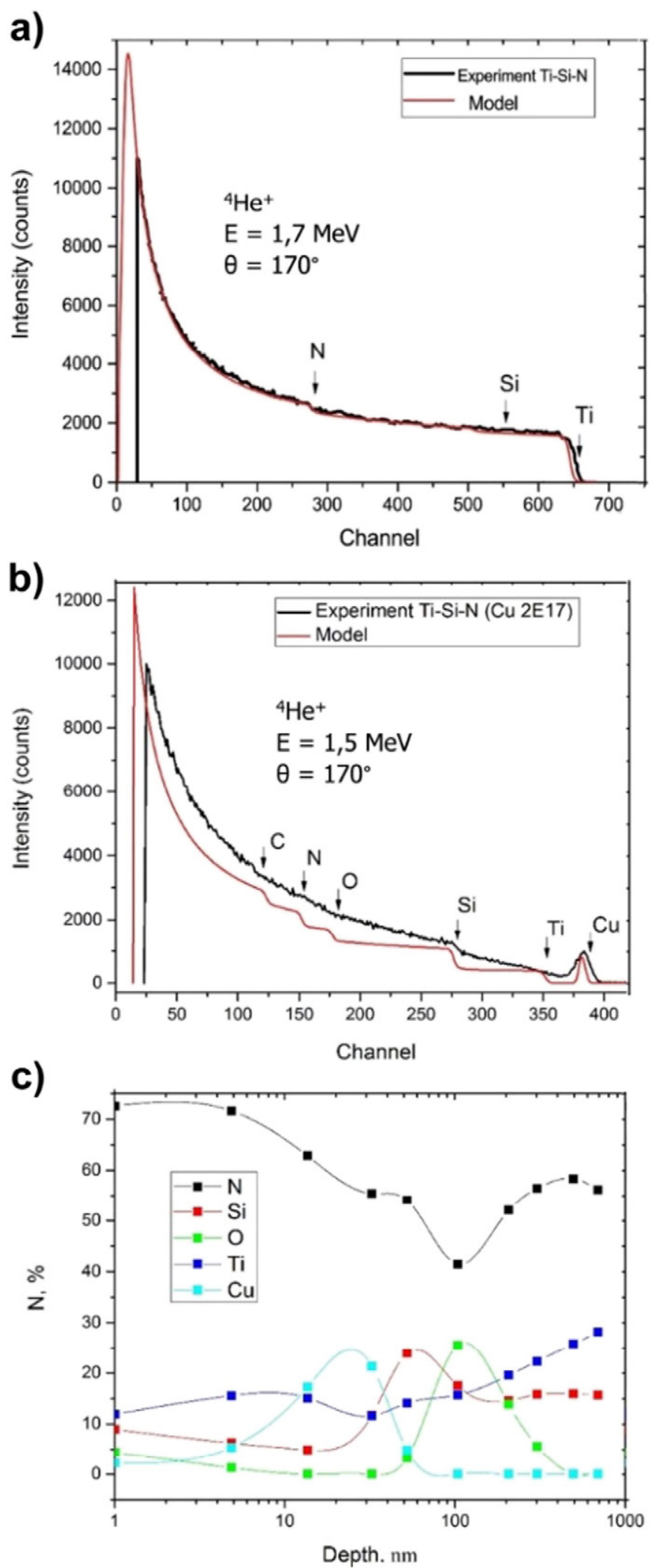

Fig. 3. Energy RBS spectra obtained for coatings: (a) - Ti-Si-N as-deposited, (b) - Ti-Si-N after ion implantation by $\mathrm{Cu}^{-}$ions with $\mathrm{D}=2 \times 10^{17} \mathrm{ions} / \mathrm{cm}^{2}, \mathrm{E}=60 \mathrm{keV}$, (c) - element distribution over depth for the coatings Ti-Si-N after implantation ions $\mathrm{Cu}^{-}\left(2 \times 10^{17}\right.$ ions/ $\mathrm{cm}^{2}$ ).

in the regions, which can be easily observed in the Fig. 4b. PIXE-method is not suitable to show such light elements as oxygen and nitrogen, thus we focus on $\mathrm{Ti}, \mathrm{Cu}$ and $\mathrm{Si}$ [38-40].

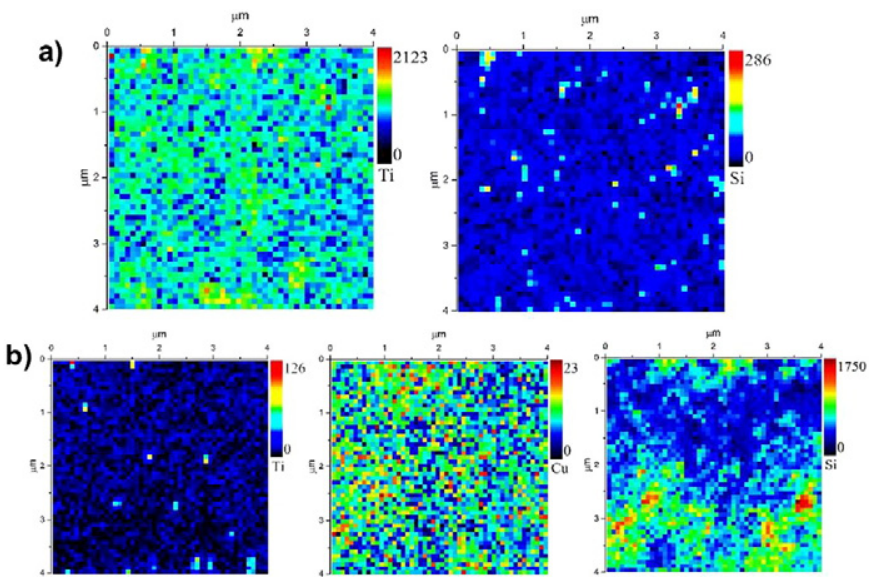

Fig. 4. Element map for a sample fragment with sizes of $2.5 \times 2.5 \mu \mathrm{m}(50 \times 50$ raster and scanning step of $0.5 \mu \mathrm{m}$ ) for the sample of the Ti-Si-N (as-deposited) (a), Ti (left), $\mathrm{Si}$ (right)(b) after ion implantation by $\mathrm{Cu}^{-}$ions with $\mathrm{D}=2 \times 10^{17} \mathrm{ions} / \mathrm{cm}^{2}, \mathrm{E}=60 \mathrm{keV}$ $\mathrm{Ti}($ left), $\mathrm{Cu}$ (centre) and Si(right).

Near Edge X-ray Absorption Fine Structure is presented in Fig. 5. All collected spectra were normalized to the incoming photon beam intensity. Fig. 5a presents NEXAFS spectra where three well defined lines, corresponding to Ti L-edge, Si L-edge and $\mathrm{N}$ K-edge of the pure Ti-Si$\mathrm{N}$, can be observed. Complicated shape of Ti and N signals can be explained by several chemicals interactions in the sample, compatible with the Ti-Si-N, $\mathrm{Ti}_{2} \mathrm{~N}$ and TiN crystalline structure observed before. It is important to remember that NEXAFS method can provide superficial information, typically $3-5 \mathrm{~nm}$ of the samples. Fig. 5 b shows NEXAFS spectra of Ti L-edge, Cu L-edge and N K-edge of the Ti-Si-N sample after ion implantation by $\mathrm{Cu}$ ions. Results suggest the strong oxidation of the sample is reflected in very pronounced shoulders at $\mathrm{Ti}$ and $\mathrm{Cu} \mathrm{L}-$ edges. Furthermore, the weak signal of the N K-edge shows the important contribution of the $\mathrm{Cu}$ and Ti atoms on top of the sample. Substantial difference in the Ti L-edges and N K-edge of two samples was observed. This observations suggests, that Ti and $\mathrm{N}$ atoms have different chemical interactions due to the $\mathrm{Cu}$ implantation, which cause by evaporation of the $\mathrm{N}$ atoms and recrystallization of the TiN into $\mathrm{Ti}_{2} \mathrm{~N}$ as shown in XRD. This results correlate with EDX measurements, where rapid drop of $\mathrm{N}$ signal was detected in comparison to pure Ti-Si-N [41].

Transmission electron micrograph, presented in Fig. 6a, shows the crystalline nature of the films and Fig. 6b shows the distribution of the elements in the $\mathrm{Cu}$ implanted coating. The coating displays a highly crystalline composition, which is compatible with the results presented in XRD micrographs, with a columnar growth mechanism. The total thickness of the coating was found to be $1.2 \mu \mathrm{m}$. The electron diffraction pattern (SAED), presented in Fig. 6a, shows a clear set of spots corresponding to Ti-Si-N (ICCD-PDF: 04-001-9273), and $\mathrm{Ti}_{2} \mathrm{~N}$ (ICCD-PDF: 01-080-3438), which is compatible with the XRD data. The elemental composition of the coatings was determined by EDX measurements, energy dispersive spectra of the coating was analysed and major components resolved. Peaks from $\mathrm{Si}, \mathrm{N}$ and Ti can be clearly observed and their values were identified as $\mathrm{Ti}=43.9 \% \mathrm{Si}=0.30 \% \mathrm{~N}=49.5 \%$, showing the rather low doping of the $\mathrm{Ti}_{1}{ }_{-} \mathrm{Si}_{\mathrm{x}} \mathrm{N}$ unit cells with $\mathrm{Si}$. It is important to remark that the cross section was placed in a $\mathrm{Cu}$ grid, thus the sample would show small contributions of $\mathrm{Cu}$ and $\mathrm{C}$ at any point of measurements. Nonetheless, cross section analysis content shows the clear concentration of $\mathrm{Cu}$ ions at depths of 60-70 nm, Fig. 6b, region that was also observed in RBS studies. Composition extracted from the area marked with red dashed lines, shows $\mathrm{Ti}=40.67 \% \mathrm{Si}=0.34 \% \mathrm{~N}=$ $45.22 \%$ and $\mathrm{Cu}=13.78 \%$ while the $\mathrm{Cu}$ concentration at any other depths remains close to $7 \%$. Nevertheless the values are congruent with the results of RBS, previously presented in this communication. The low $\mathrm{Si}$ presence and the slight changes on the TiN valences and structure, suggest the stabilization of solid solution of $(\mathrm{Ti}, \mathrm{Si})$ nitride in the as- 

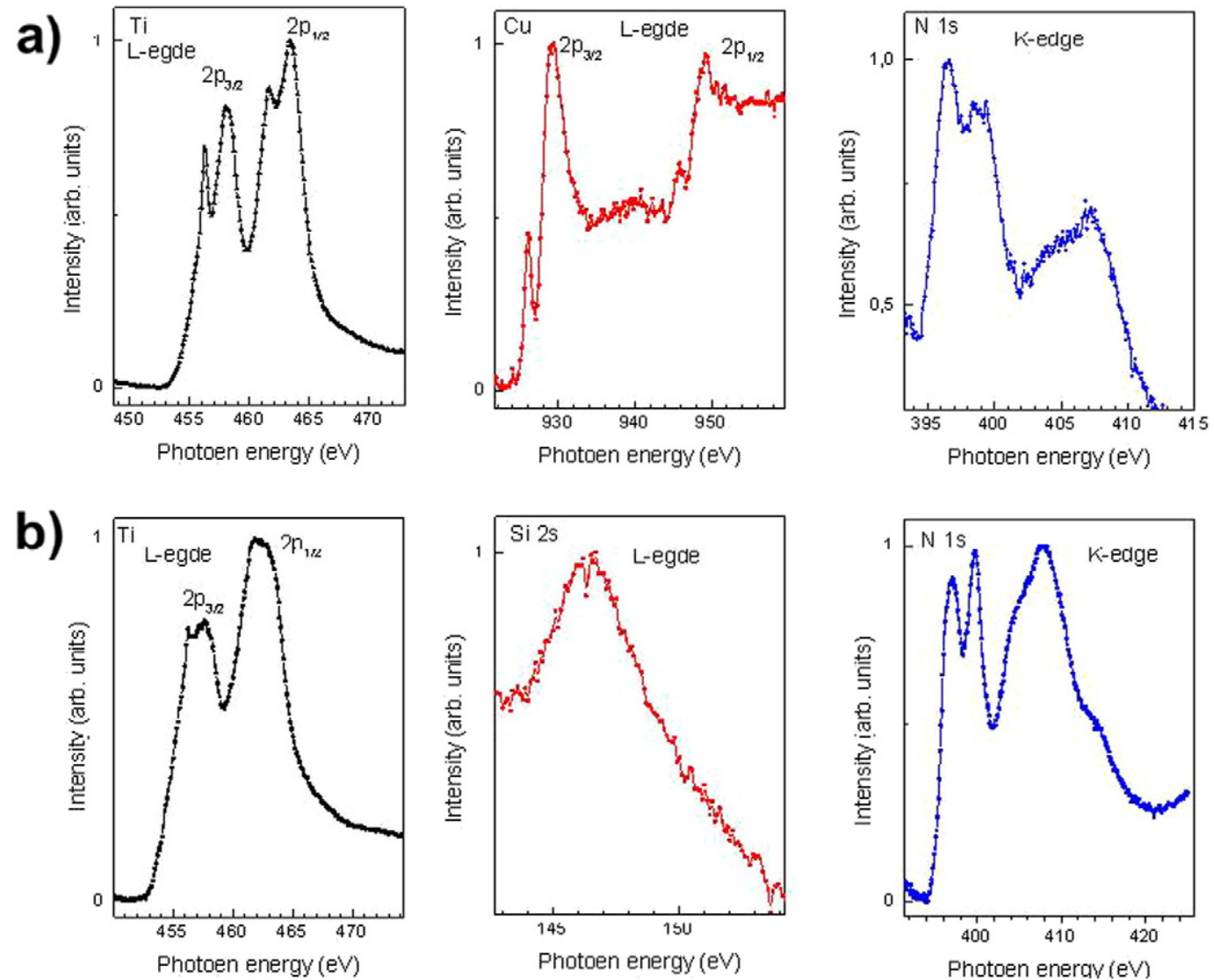

Fig. 5. NEXAFS spectra of pure Ti-Si-N (a) and Ti-Si-N after ion implantation by $\mathrm{Cu}^{-}$ions with $\left.\mathrm{D}=2 \times 10^{17}{\text { ions } / \mathrm{cm}^{2}}^{2} \mathrm{~b}\right)$, respectively.

a)

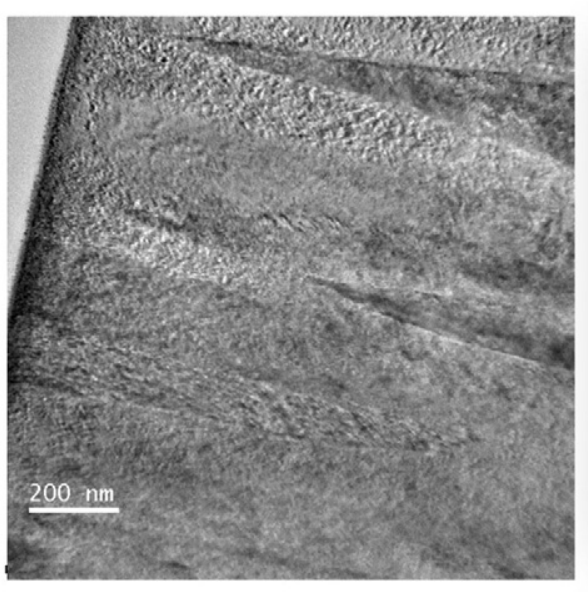

b)

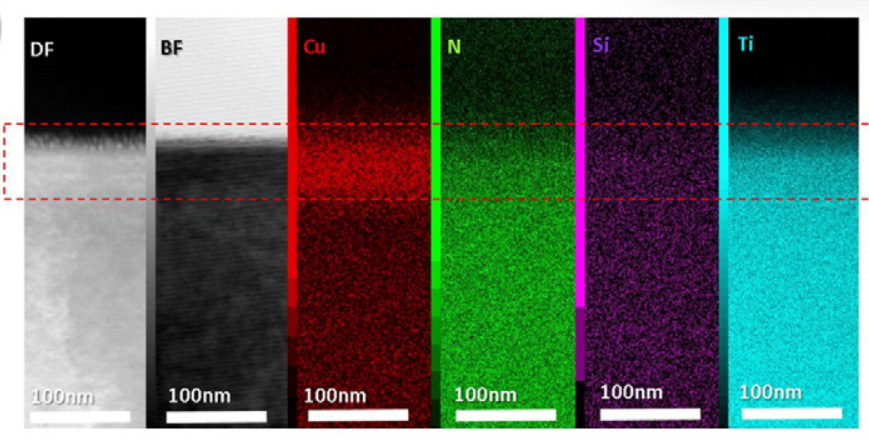

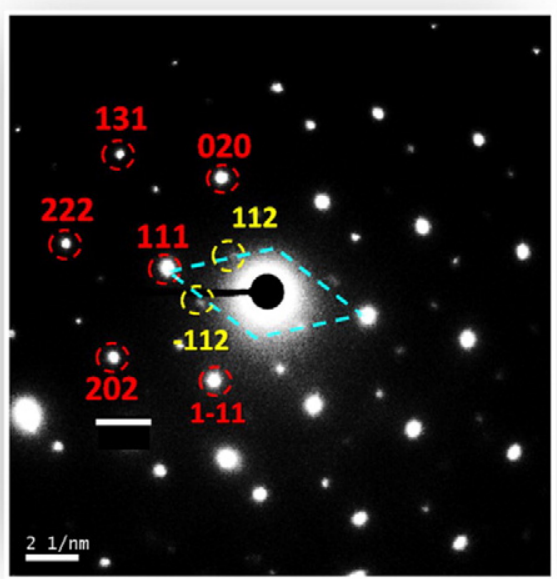

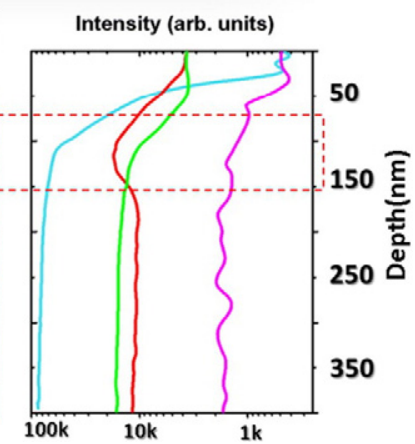

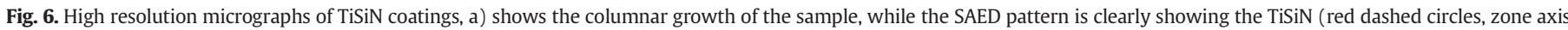
[-101]) and $\mathrm{Ti}_{2} \mathrm{~N}$ (yellow dashed circles, zone axis [0-11]), b) shows the EDX elemental mapping of the sample with intensity profile of the signals (log scale for clarity). 
deposited coating. Moreover, the amount of $\mathrm{Si}$ is not sufficient to hinder the grain growth during deposition and for segregation at grain boundaries to form two crystalline phases of the coating. Therefore, columnar structure of the coating is observed. The volume fraction of $(\mathrm{Ti}, \mathrm{Si}) \mathrm{N}$ decreases after ion implantation of $\mathrm{Cu}$ ions due to metastable state of ( $\mathrm{Ti}$, $\mathrm{Si}) \mathrm{N}$ with simultaneous increasing of more thermodynamically favourable $\mathrm{Ti}_{2} \mathrm{~N}$, which was well demonstrated by XRD. The possible explanation of this phenomenon is a complementary interaction of implantation induced annealing and radiation damage.

Nanoindentation measurements were conducted using a multiple load function applied to a diamond Berkovich tip with maximum loads from $0.05 \mu \mathrm{N}$ to $10 \mathrm{mN}$ in order to measure hardness $(\mathrm{H})$ and reduced elastic modulus $\left(E_{\mathrm{r}}\right)$ at different depths. Nanoindentation experiments for both as-deposited and $\mathrm{Cu}$ implanted Ti-Si-N coatings were performed by a partial load/unload function with maximum penetration of $80 \mathrm{~nm}$, well above the maximum Cu concentration of the implanted sample. As it can be observed in Fig. 7, the extracted values of hardness and elastic modulus, based on Oliver-Pharr method, show an average hardness of $23.52 \mathrm{GPa}$ and reduced elastic modulus of $320 \mathrm{GPa}$ for the as-deposited sample. Ion implantation of $\mathrm{Cu}$ ions with $\mathrm{D}=2 \times 10^{17}$ ions $/ \mathrm{cm}^{2}, \mathrm{E}=60 \mathrm{keV}$ leads to slight decrease of reduced elastic modulus to value $290 \mathrm{GPa}$ at the depth $30 \mathrm{~nm}$, increasing to the value $320 \mathrm{GPa}$ at depth corresponding with the highest $\mathrm{Cu}$ concentration. The average hardness value has the same tendency being $\sim 20.36 \mathrm{GPa}$ at the depth up to $30 \mathrm{~nm}$ with further increasing up to $22 \mathrm{GPa}$ at the depth $45-65 \mathrm{~nm}$.

Elastic strain prior to plastic deformation $\left(\mathrm{H} / \mathrm{E}_{\mathrm{r}}\right)$ (Fig. 7c) and resistance to plastic deformation $\mathrm{H}^{3} / \mathrm{E}_{\mathrm{r}}^{2}$ (Fig. 7d) of the coatings had the same tendency as the hardness and reduced elastic modulus (Fig. 7c, d). Nevertheless, the implanted coating has worse elastic strain prior to the plastic deformation after $30 \mathrm{~nm}$, depth at which the hardness values are reliable, which will decrease its wear resistance $[3,4,13,21$, 22]. Moreover, the resistance of the Ti-Si-N coating to the formation of cracks $\left(\mathrm{H}^{3} / \mathrm{E}_{\mathrm{r}}^{2}\right)$ decreases after $\mathrm{Cu}$ ion implantation, which is well visible in Fig. 7d. The decrease of mechanical properties of the Ti-Si-N coating after $\mathrm{Cu}$ ion implantation can be explained by two possible mechanisms. The first possible reason is attributed to the softer Cu-based phase, caused by ion implantation, as shown previously; the surface of the coating has strong contributions of Ti-Cu with rather low Si and N. Another possible explanation is radiation damage, which causes displacements occurring in response to "knock-on" collisions leading to the formation of displacement spikes whose cores may be amorphous. Each such spike will behave as a small second-phase particle in an otherwise damaged matrix and interact with dislocations. The real scenario may be a mixture of both mechanism [38,39,42-45].

Finally, antibacterial efficiency of the films was evaluated and presented in Fig. 8. It is generally acknowledged that copper doping with values higher than $20 \%$ show detectable antibacterial efficiency, while maximum performance is the highest with concentrations above $65 \%$ [46-48]. In the samples studied in this article, the total doping on the surface was estimated as $<20 \%$, so it was expected that after the $\mathrm{Cu}$ implantation, with a rather low dosage, the bioactivity of the samples was scarce. Antibacterial efficiency tests showed the low bioactivity of the films during the exposure time used, results show similar behaviour as the ones reported by J. Musil et al. [48] for $\mathrm{Cr}$-Cu-O coatings, with almost indistinguishable effect of low Cu doping on the bioactivity of the samples. Elemental analysis of the surfaces after immersion in the cultivation liquid for 5 h shows the following values: $\mathrm{C}=14.51 \%, \mathrm{~N}=$
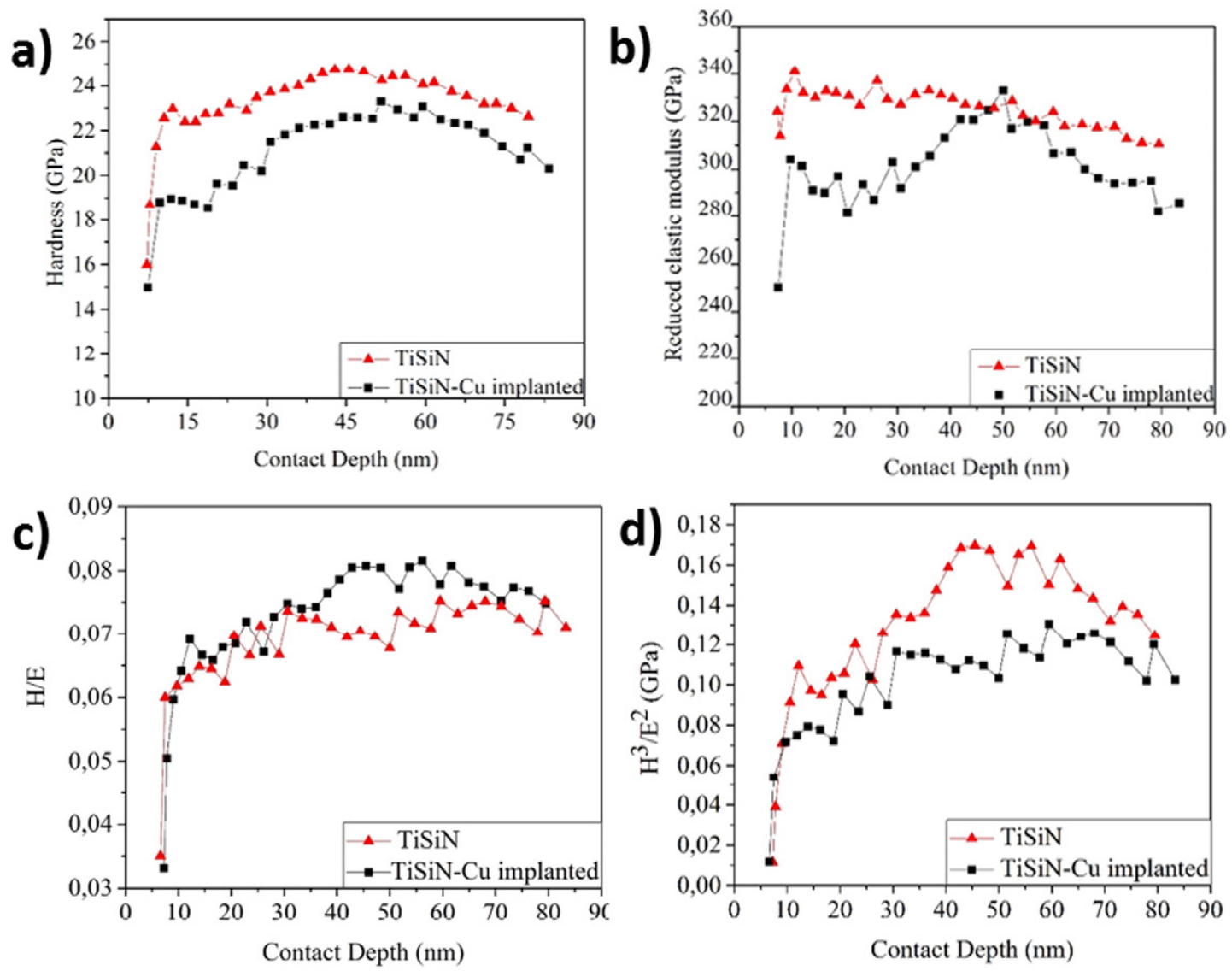

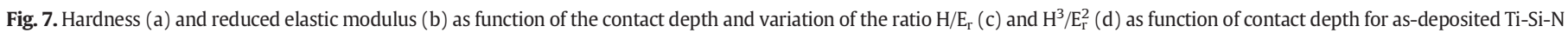
coating and after ion implantation of $\mathrm{Cu}^{-}$ions with $\mathrm{D}=2 \times 10^{17}$ ions $/ \mathrm{cm}^{2}, \mathrm{E}=60 \mathrm{keV}$. 

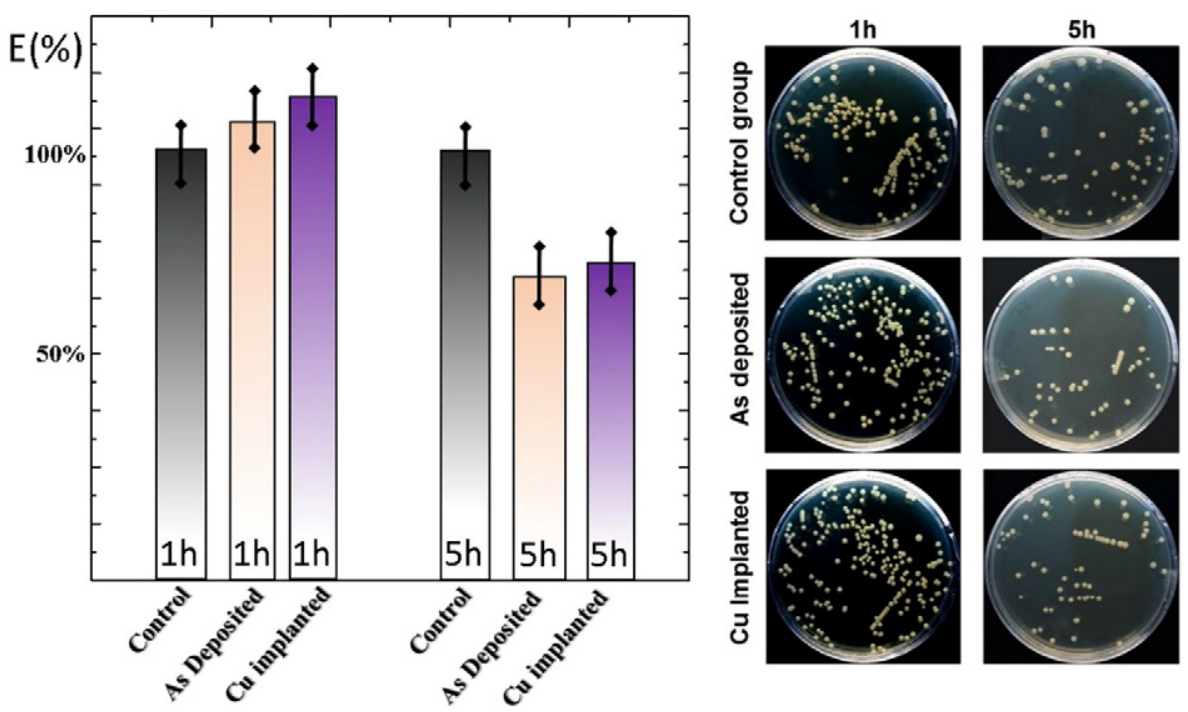

Fig. 8. Antibacterial efficiency E of as-deposited Ti-Si-N and Cu doped surfaces (left) and pictures of the cultivation plates (right).

$36.03 \%, \mathrm{O}=15.28 \%, \mathrm{Si}=0.5 \%, \mathrm{Ti}=31.85 \%$ and $\mathrm{Cu}=1.83 \%$. Results clearly point to a decrease of $\mathrm{Cu}$ and $\mathrm{N}$ content, while the oxidation of the samples is evident.

Our findings are similar to the ones reported by B. Finke et al. [49] and V. Stranaka et al. [50,51] in which ion implanted Cu surfaces, with doses ranging from $0.7 \times 10^{17}$ to $63.5 \times 10^{17}$ ions $/ \mathrm{cm}^{2}$ were used, had lower antibacterial efficiency than surfaces prepared by high pulse magnetron sputtering and the rapid release of $\mathrm{Cu}$ was strongly dependent of grain size. This shows the rapid release of $\mathrm{Cu}$ ions to the cultivation liquid and is compatible with previous results, in which the first hours of exposure are those in which a bigger $\mathrm{Cu}$ release takes place [48].

\section{Conclusions}

The effect of ion implantation on the physical and mechanical properties of the coatings was studied. The structure of Ti-Si-N coatings on steel was investigated by means of nanoindentation, XRD, SEM (EDS), RBS, $\mu$-PIXE, NEXAFS and TEM. Phase analysis showed that the main crystalline structures, in the as-deposited coating, were $(\mathrm{Ti}, \mathrm{Si}) \mathrm{N}$, followed by $\mathrm{TiN}_{\mathrm{N}}$ and $\mathrm{Ti}_{2} \mathrm{~N}$. Our investigations showed that ion implantation leads to a decrease in grains size and lattice parameter and a worsening of the hardness of the coating (20.36 GPa) and elastic modulus (301 GPa). Bioactivity towards E. coli bacteria was studied showing poor antimicrobial effect and rapid Cu release, with 16\% of $\mathrm{Cu}$ lost under $5 \mathrm{~h}$. The results show the poor stability of the $\mathrm{Cu}$ doped surface under the studied conditions and the negative effect on the overall mechanical properties of the films.

Finally, although $\mathrm{Cu}$ implantation is a promising and widely studied technique, which has shown an increment of plasticity of the sample, its applicability on bioactive surfaces strongly depends on the ion dosage. The burst effect associated with the rapid release of the $\mathrm{Cu}$ ions into the incubation media, although effective for high implantation dosage, could prove inefficient for long lasting functional surfaces and harmful for the environment. Nevertheless, our results serve as a benchmark of the drawbacks of ion implantation on bioactive surface.

Furthers studies are needed in order to understand the burst release effect of these surfaces and generate long lasting bioactive surfaces with fully immobilized $\mathrm{Cu}$ ions as antibacterial agent.

\section{Acknowledgments}

This work was done with the financial support of the Erasmus Mundus EMINENCE partnership. The authors are grateful to Vladislav Rogoz (Sumy State University) for collaboration regarding the interpretation of XRD and RBS results. We acknowledge MAX-IV Laboratory for providing beam-time. Authors acknowledge the partial financial support from the National Science Centre of Poland by the PRELUDIUM projects number UMO-2015/17/N/ST5/01988 (by EC) and UMO-2015/19/N/ST5/01764 (by A.S \& A.P).

\section{References}

[1] H. Gleiter, Prog. Mater. Sci. 33 (1989) 233.

[2] R.W. Siegel, Annu. Rev. Mater. Sci. 21 (1991) 559

[3] S. Veprek, S.A. Reiprich, Thin Solid Films 268 (1995) 64.

[4] A.D. Pogrebnyak, A.P. Shpak, N.A. Azarenkov, V.M. Beresnev, Phys. Usp. 52 (2009) 29.

[5] P.H. Mayrhofer, C. Mitterer, L. Hultman, H. Clemens, Prog. Mater. Sci. 51 (2006) 1032.

[6] J. Musil, Surf. Coat. Technol. 125 (2000) 322.

[7] R.A. Andrievski, Russ. Chem. Rev. 74 (2005) 1061.

[8] J. Musil, Surf. Coat. Technol. 207 (2012) 50.

[9] D.V. Shtanski, S.A. Kulinich, E.A. Levashov, J.J. Moore, Phys. Solid State 45 (2003) 1177.

10] S. Vepřek, J. Vac. Sci. Technol. A 17 (1999) 2401.

[11] J.J.A.M. Van Raay, P.M. Rozing, C.A. Van Blitterswijk, R.M. Van Haastert, H.K.I. Dion, X. Roques, N. More, L. Labrousse, J. Caix, F. Lefebvre, F. Rouais, J. Gautreau, C. Baquey, Biomaterials 14 (1993) 712.

[12] J.J.A.M. Raay, P.M. Rozing, C.A. Van Blitterswijk, H.K. Koerten, J. Mater. Sci. Mater. Med. 6 (1995) 80.

[13] A.D. Pogrebnjak, A.G. Ponomarev, A.P. Shpak, Y.A. Kunitskii, Phys.-Usp. 55 (2012) 270.

[14] D.V. Shtansky, N.A. Gloushankova, I.A. Bashkova, M.I. Petrzhik, A.N. Sheveiko, F.V Kiryukhantsev-Korneev, I.V. Reshetov, A.S. Grigoryan, E.A. Levashov, Surf. Coat. Technol. 201 (2006) 4111.

[15] L. Yate, L.E. Coy, D. Gregurec, W. Aperador, S.E. Moya, G. Wang, ACS Appl. Mater. Interfaces 7 (2015) 6351.

[16] S. Mändl, B Rauschenbacha, Surf. Coat. Technol. 156 (2002) 276.

[17] P.A. Dearnley, Proceedings of the Institution of Mechanical Engineers, Part H. (J. Eng. MEd.), 213, Professional Eng. Publ., London, 1999107.

[18] S. Piscaneca, L.C. Ciacchib, E. Vesselli, G. Comelli, O. Sbaizero, S. Meriani, A. De Vita, Acta Mater. 52 (2004) 1237.

[19] D.V. Shtansky, N.A. Gloushankova, A.N. Sheveiko, M.A. Kharitonova, T.G. Moizhess, E.A. Levashov, F. Rossi, Biomaterials 26 (2005) 2909.

[20] T. Kokubo, H. Kim, M. Kawashita, Biomaterials 24 (2003) 2161.

[21] A. Pogrebnjak, M. Danilionok, V. Uglov, N. Erdybaeva, G. Kirik, S. Dub, V. Rusakov, A. Shypylenko, P. Zukovski, Y. Tuleushev, Vacuum 83 (2009) S235.

[22] A.D. Pogrebnjak, V.V. Uglov, M.V. Il'yashenko, V.M. Beresnev, A.P. Shpak, M.V. Kaverin, N.K. Erdybaeva, Y.A. Kunitskyi, Y.N. Tyurin, O.V. Kolisnichenko, N.A. Makhmudov, A.P. Shypylenko, Ceram. Eng. Sci. Proc. 31 (2010) 127.

[23] A.D. Pogrebnjak, A.M. Tolopa, Nucl. Instrum. Methods Phys. Res., Sect. B 52 (1990) 25.

[24] A. Pogrebnjak, S. Bratushka, N. Levintant-Zayonts, J. Nanoelectron. Phys. 5 (2013) 01016.

[25] R. Martınez, J.A. Garcia, R.J. Rodriguez, B. Lerga, C. Labrugere, M. Lahaye, A. Guette, Surf. Coat. Technol. 174-175 (2003) 1253.

[26] B. Tian, W. Yue, Z. Fu, Y. Gu, C. Wang, J. Liu, Vacuum 99 (2014) 68.

[27] J. Fidler, A. Kolitsch, B. Kleffner, G. Henke, S. Stenger, R.E. Brenner, Int. J. Artif. Organs 9 (2011) 882-888.

[28] J. Liu, F. Li, C. Liu, H. Wang, B. Ren, K. Yang, E. Zhang, Mater. Sci. Eng. C 35 (2014) 392.

[29] I.T. Hong, C.H. Koo, Mater. Sci. Eng. A 393 (2005) 213.

[30] J. Banas, A. Mazurkiewicz, Mater. Sci. Eng. A 277 (2000) 183. 
[31] L. Nan, K. Yang, J. Mater. Sci. Technol. 26 (2010) 941.

[32] G. Jin, H. Qin, H. Cao, S. Qian, Y. Zhao, X. Peng, X. Zhang, X. Liu, P.K. Chu, Biomaterials 35 (2014) 7699

[33] N. Kishimoto, Y. Umeda, C. Takeda, G. Lee, V.T. Gritsyna, Nucl. Inst. Methods Phys. Res. B 148 (1999) 1017

[34] A.D. Pogrebnjak, S.N. Bratushka, V.M. Beresnev, N. Levintant-Zayonts, Russ. Chem. Rev. 82 (2013) 1135.

[35] A.V. Nikonenko, N.A. Popova, E.L. Nikonenko, M.P. Kalashnikov, A. Kurzina, IOP Conf. Ser.: Mater. Sci. Eng. 112, 2016012032.

[36] R.A. Young, D.I. Wiles, J. Appl. Crystallogr. 15 (1982) 430.

[37] W. Kraus, G. Nolze, J. Appl. Crystallogr. 29 (1996) 301.

[38] A.D. Pogrebnjak, J. Nanomater. 2013 (2013) 780125.

[39] A.V. Pshyk, L.E. Coy, L. Yate, K. Zaleski, G. Nowaczyk, A.D. Pogrebnjak, S. Jurga, Mater Des. 94 (2016) 230.

[40] V. Ivashchenko, S. Veprek, A. Pogrebnjak, B. Postolnyi, Sci. Technol. Adv. Mater. 15 (2014) 025007.

[41] A. Kowalik, G. Öhrwall, B.N. Jensen, R. Sankari, E. Wallén, U. Johansson, O. Karis, D. Arvanitis, J. Phys. Conf. Ser. 211 (2010) 012030.

[42] L. Pan, Y. Bai, D. Zhang, J. Wang, Rare Metals 31 (2012) 183.
[43] M.S. Ahmed, M. Paul, Z.-T. Jiang, X. Zhao, W. Rickard, Z.-F. Zhou, L.K.Y. Li, Z. Xie, Corros. Sci. 53 (2011) 3678.

[44] J. Fiedler, A. Kolitsch, B. Kleffner, D. Henke, S. Stenger, R.E. Brenner, Int. J. Artif. Organs 34 (2011) 882.

[45] A.D. Pogrebnjak, G. Abadias, O.V. Bondar, O.V. Sobol, V.M. Beresnev, A.V. Pshyk, A.A. Demianenko, K.O. Belovol, D.A. Kolesnikov, H. Komsta, Acta Phys. Pol. A, 125 (2014) 1284.

[46] D.L. Alontseva, S.N. Bratushka, A.A. Borysenko, A.A. Drobyshevska, I.A. Kulik, N.V. Prokhorenkova, A.V. Pshyk, V.N. Rogoz, Metallofiz. Noveishie Tekhnol. 33 (2011) 721.

[47] N. Fredj, J.S. Kolar, D.M. Prichard, T.D. Burleigh, Corros. Sci. 76 (2013) 415.

[48] J. Musil, J. Blažek, K. Fajfrlík, R. Čerstvý, Š. Prokšová, Appl. Surf. Sci. 276 (2013) 660.

[49] B. Finke, M. Polak, F. Hempel, H. Rebl, C. Zietz, V. Stranak, G. Lukowski, R. Hippler, R. Bader, J.B. Nebe, K.-D. Weltmann, K. Schröder, Adv. Eng. Mater. 14 (2012) B224.

[50] V. Stranaka, H. Wulff, P. Ksirova, C. Zietz, S. Drache, M. Cada, Z. Hubicka, R. Bader, M. Tichy, C.A. Helm, R. Hippler, Thin Solid Films 550 (2014) 389.

[51] V. Stranaka, H. Wulffa, H. Reblb, C. Zietzc, K. Arndtd, R. Bogdanowicza, B. Nebeb, R. Baderc, A. Podbielskid, Z. Hubickae, R. Hipplera, 2011, 31, 1512 